\title{
Menopausal syndrome: clinical presentation and management
}

\author{
Sunil Somnath Patil*, Pradip Wamanrao Sambarey, Chandrakala Sunil Patil
}

Department of obstetrics and gynaecology, B J Gov. Medical College and Sassoon Hospital, Pune, Maharashtra, India

Received: 09 January 2016

Revised: 08 February 2016

Accepted: 09 February 2016

\section{*Correspondence:}

Dr. Sunil Somnath Patil,

E-mail: sunilpatil0332@gmail.com

Copyright: (C) the author(s), publisher and licensee Medip Academy. This is an open-access article distributed under the terms of the Creative Commons Attribution Non-Commercial License, which permits unrestricted non-commercial use, distribution, and reproduction in any medium, provided the original work is properly cited.

\begin{abstract}
Background: Menopause is physiological stage in woman's life. Although most of women accept them, some do have a disturbed life due to various symptoms, mostly because of estrogen deprivation.

Methods: This is a prospective clinical study of 200 menopausal women attending the gynaecology OPD or admitted in the wards with various symptoms as well as some gynaecological problems. Young women with surgically induced menopause and women with psychiatric disorders were excluded.

Results: The duration between menopause and appearance of symptoms varied from $1 \mathrm{yr}$ to $10 \mathrm{yrs}$. The average age of menopause in our study was 46.5 yrs. Vasomotor symptoms $(65 \%)$ were common followed by psychosomatic symptoms $(62 \%)$, vaginal dryness $(45 \%)$ and urinary symptoms $(40 \%)$. Stress, irritability, sleep problem, weight gain were some of common presentations to OPD. Urinary incontinence and atrophic vaginitis were also seen predominantly. The management consists mainly of counseling and life style modification, exercise, yoga meditation etc. Some of the women required estrogen cream, 70 women required surgical treatment. Overall the response to various medications was satisfactory and on follow up the symptoms was found to be much less.

Conclusions: There is need of setting menopausal clinics and centres to help women with symptoms and signs of estrogen deprivation. Counseling and education are main treatment modalities.
\end{abstract}

Keywords: Menopause, Estrogen, Vasomotor symptoms

\section{INTRODUCTION}

Term 'menopause' is derived from the Latin word Meno (month) and Pausia (halt). Menopause essentially marks the end of a women's period of natural fertility. As a woman approaches menopause, the number of ovarian follicles decline, producing less estrogen and causing irregular menstrual periods. Eventually, the quantity of estrogen produced is too low to maintain the monthly menstrual cycle. ${ }^{1}$ The next stage is referred to as the menopausal syndrome which ranges from hot flushes, irritability to osteoporosis and heart disease and is experienced by all women in varying degree. Climacteric syndrome is characterized by various symptoms like cessation of menstruation, hot flushes, insomnia, vaginal dryness, weight gain, mood swings, depression, slowed thinking. Urogenital atrophy causes vaginal dryness, dyspareunia, discharge, incontinence, dysuria and recurrent UTI. Epidemiological data indicates that menopausal women are at high risk of developing coronary heart disease. The cardioprotective effect of estrogen is due to its influence on lipid and lipoprotein metabolism as well as other chemical mediators which influence circulation. Osetoporosis affect women`s health and with increasing life expectancy, future incidence of osteoporosis related factors will increase greatly. Estrogen play an important role in maintaining bone balance and its deficiency causes rapid bone loss particularly in spinal column leading to osteoporosis. The average age of Menopause is 51 years old but there is no way to predict when an individual woman will enter Menopause. As most of communities in india are staying 
in rural areas and are from low socioeconomic status, it will be worthwhile to find out the clinical presentation of women of naturally occurring menopause and effectively of natural estrogens along with dietary supplement and exercise to combat these menopausal symptoms.

In this study we have observed 100 cases of women with natural menopause, their demographic status, clinical presentation and general and specific management.

\section{Aims and objectives}

1. To study clinical presentation of menopausal women.

2. To study various gynaecological problems and management of symptoms if require.

\section{METHODS}

This is a prospective clinical study. 200 menopausal women taking treatment at General Hospital are included in the study from $1^{\text {st }}$ January 2012 to 31 December 2014.

\section{Inclusion criteria}

All menopausal women either be attending the gynaecology OPD or admitted in the wards with some gynaecological disorders.

\section{Exclusion criteria}

Young women with surgically induced menopause and women with psychiatric disorders.

Initially consent of the patients was taken before subjecting them to any investigation and surgical and medical intervention if required. These patients were studied and evaluated in details with history including menstrual, obstetric, social and psychological background, socioeconomic background, and clinical symptoms if present. All these women were examined in details. The examination included general examination including breast examination, systemic examination, local examination, perspeculum and pervaginal examination. The women were subjected to following investigations: hemoglobin estimation, E.C.G., fasting BSL, vaginal cytology, pelvic ultrasound, mammogram, colposcopy etc which were carried out in the same hospital.

The women with menopausal symptoms were treated accordingly. Initially all were counselled and importance of meditation, yoga, exercises, proper diet. Medical management of diabetes, hypertension and urinary infection if any was given as per requirement. The surgical conditions diagnosed on clinical examination and ultrasonography like fibroids, prolapse, malignancies, ovarian tumours were treated accordingly. Cervical lesions diagnosed on colposcopy and biopsy was treated with cauterization, conisation, amputation or hysterectomy. Breast problems were referred to surgeons and were given treatment as per the case. The cases with oestrogen deficiency diagnosed on clinical findings and investigations are managed with local and systemic administration of oestrogen. Treatment with phytoestrogens and other non-hormonal therapy were given in many cases. All those cases were followed carefully and the response to various therapies was studied. All the findings were tabled and analysed statistically to study the importance of problems of management and need to study these women.

\section{RESULTS}

Maximum age was $53 \mathrm{yr}$ and minimum age was $40 \mathrm{yrs}$. Average age of menopause of study is $46.5 \mathrm{yrs}$. Most of women presented within 1-5 yrs of menopause.

Table 1: Age at time of menopause and age of women attending opd with symptoms and duration of menopause and occurance of symptom.

\begin{tabular}{|lllllllll|}
\hline Age at & $\begin{array}{l}\text { Ages } \\
\text { time of } \\
\text { menopause }\end{array}$ & $\begin{array}{l}\text { Cases } \\
(200)\end{array}$ & SN & $\begin{array}{l}\text { Age at } \\
\text { presentation }\end{array}$ & $\begin{array}{l}\text { Cases } \\
(200)\end{array}$ & SN & $\begin{array}{l}\text { Duration of menopause } \\
\text { and occurrence } \\
\text { of symptoms }\end{array}$ & $\begin{array}{l}\text { Cases } \\
(200)\end{array}$ \\
\hline 1 & $<40$ yrs & 0 & 1 & Less than 45 & $10(5 \%)$ & 1 & $1-2$ yrs & $64(32 \%)$ \\
\hline 2 & $40-45$ yrs & $100(50 \%)$ & 2 & $45-50$ & $140(70 \%)$ & 2 & $2-5$ yrs & $60(30 \%)$ \\
\hline 3 & $46-50$ yrs & $50(25 \%)$ & 3 & $51-55$ & $20(10 \%)$ & 3 & $5-10$ yrs & $36(18 \%)$ \\
\hline 4 & $>50$ yrs & $50(25 \%)$ & 4 & More than 55 & $30(15 \%)$ & 4 & More than 10 yrs & $40(20 \%)$ \\
\hline
\end{tabular}

Table 2: Women general profile.

\begin{tabular}{|lllllllll|}
\hline SN & Occupation & Cases $(200)$ & SN & Education & Cases $(200)$ & SN & Residence & Cases $(200)$ \\
\hline 1 & Housewife & $124(62 \%)$ & 1 & No education & $50(25 \%)$ & 1 & Urban & $20(10 \%)$ \\
\hline 2 & Office going & $20(10 \%)$ & 2 & Up to $4^{\text {th }}$ std & $106(53 \%)$ & 2 & Rural & $160(80 \%)$ \\
\hline 3 & Farmer & $48(24 \%)$ & 3 & $4^{\text {th }}$ to $10^{\text {th }}$ std & $24(12 \%)$ & 3 & Slums & $20(10 \%)$ \\
\hline 4 & Other & $08(4 \%)$ & 4 & $10^{\text {th }}$ std onwards & $20(10 \%)$ & 4 & & \\
\hline
\end{tabular}


Most of the women in this study were either housewives $(62 \%)$ or working in the field $(24 \%)$. Most of the women were residing in rural areas. The literacy status of the women was poor as only $53 \%$ the women were educated upto $4^{\text {th }}$ std and $25 \%$ women did not obtain any education. In our study only 2 women were not married. Most of women (90\%) were from low socioeconomic status.

Table 3: Family size and response from family members and marital status.

\begin{tabular}{|llll|}
\hline SN & Response from family members & & \\
\hline 1 & Neglected by family/husband & 8 & $4 \%$ \\
\hline 2 & $\begin{array}{l}\text { Positive support from } \\
\text { family/husband }\end{array}$ & 120 & $60 \%$ \\
\hline 3 & $\begin{array}{l}\text { Negative/ less support from } \\
\text { family/husband }\end{array}$ & 72 & $36 \%$ \\
\hline
\end{tabular}

Table 4: Menopausal symptoms.

\begin{tabular}{|c|c|c|c|}
\hline SN & Symptoms & Cases & $\begin{array}{l}\text { Duration } \\
\text { between } \\
\text { menopause } \\
\text { \& symptoms }\end{array}$ \\
\hline \multicolumn{4}{|c|}{ A) Vasomotor symptoms } \\
\hline 1 & $\begin{array}{l}\text { Hot flushes and night } \\
\text { sweats }\end{array}$ & 130 & $2 \mathrm{yrs}$ \\
\hline \multicolumn{4}{|c|}{ B) Vaginal symptoms } \\
\hline 1 & Vaginal dryness & 90 & $2-5$ yrs \\
\hline 2 & Painful coitus & 40 & $2-5$ yrs \\
\hline 3 & Prolapse & 56 & $7-10$ yrs \\
\hline 4 & Vaginal discharge & 50 & $5-10$ yrs \\
\hline \multicolumn{4}{|c|}{ C) Psychological problems } \\
\hline 1 & Depression & 50 & $3-5$ yrs \\
\hline 2 & Tension & 124 & $3-5$ yrs \\
\hline 3 & Forgetfulness & 100 & $2-4$ yrs \\
\hline 4 & Poor concentration & 80 & $2-4 y r s$ \\
\hline \multicolumn{4}{|c|}{ D) Psychosomatic symptoms } \\
\hline 1 & Dizziness & 70 & $3-5$ yrs \\
\hline 2 & Palpitations & 56 & $5-7$ yrs \\
\hline 3 & Numbness & 62 & $3-5$ yrs \\
\hline 4 & Irritability & 120 & $1-2$ yrs \\
\hline 5 & Tiredness & 96 & $2-5 \mathrm{yrs}$ \\
\hline 6 & Headache & 90 & $2-5 \mathrm{yrs}$ \\
\hline 7 & Sleep problems & 90 & $2-5$ yrs \\
\hline 8 & Joint/backache & 80 & $5-7$ yrs \\
\hline 9 & Weight gain & 60 & $5-7$ yrs \\
\hline \multicolumn{4}{|c|}{ E) Urinary symptoms } \\
\hline 1 & Dysuria & 70 & $2-5$ yrs \\
\hline 2 & Frequency & 80 & $2-5 y r s$ \\
\hline 3 & $\begin{array}{l}\text { Incontinence urge+ } \\
\text { stress }\end{array}$ & 70 & $5-10$ yrs \\
\hline 4 & Incomplete emptying & 60 & $2-5 \mathrm{yrs}$ \\
\hline
\end{tabular}

Table 5: Abnormality on clinical examination and investigation.

\begin{tabular}{|llll|}
\hline SN & Abnormality & Cases & $\%$ \\
\hline 1 & Anaemia (pallor) & 84 & $42 \%$ \\
\hline 2 & Obesity & 70 & $35 \%$ \\
\hline 3 & Hypertension & 40 & $20 \%$ \\
\hline 4 & Abdominal mass(TO mass) & 04 & $02 \%$ \\
\hline 5 & Prolapse (uterus +vaginal wall) & 56 & $28 \%$ \\
\hline 6 & Vaginitis (mostly atrophic) & 64 & $32 \%$ \\
\hline 7 & Incontinence (urge + stress) & 70 & $35 \%$ \\
\hline 8 & Cervix malignancy & 10 & $05 \%$ \\
\hline 9 & Uterine enlargement (>8weeks) & 10 & $06 \%$ \\
\hline 10 & Cardiovascular disease & 02 & $01 \%$ \\
\hline
\end{tabular}

Table 6: Management.

\begin{tabular}{|lll|}
\hline SN & Management & Cases \\
\hline 1 & Counselling & 200 \\
\hline & $\begin{array}{l}\text { Medical management (Hematinics, } \\
\text { Calcium supplementation, }\end{array}$ & \\
& $\begin{array}{l}\text { Antihypertensive, Antidiabetics, } \\
\text { Antibiotics, Local estrogen, Other } \\
\text { drugs-soya, phytoestrogen, }\end{array}$ & 140 \\
& Chemotherapy for malignancy) & \\
& $\begin{array}{l}\text { Surgical management (Exploratory } \\
\text { laparotomy, Vaginal hysterectomy } \\
\text { and repair, Wertheim' hysterectomy, }\end{array}$ & \\
& Vaginal wall prolapse repair without \\
hysterectomy, Surgery for stress & 70 \\
& incontinence) & \\
\hline 4 & $\begin{array}{l}\text { Other therapies (Yoga, meditation, } \\
\text { lifestyle ,exercises, diet) }\end{array}$ & 200 \\
\hline
\end{tabular}

\section{DISCUSSION}

This was prospective, observational, informational and analytic study of 200 menopausal women coming to outpatient department with various symptoms and signs. Many of symptoms were mentioned by patients while some women narrated them on direct questioning. Some women presented with gynecological problems like prolapse, malignancies, incontinence etc. but they also had vasomotor and psychosomatic manifestations.

Maximum age of menopause was $53 \mathrm{yr}$ and minimum age was 40yrs. Average age of menopause of our study is $46.5 \mathrm{yrs}$, as most of women $(50 \%)$ had menopause before $45 y$ rs. Most of women presented in 1-5 years after reaching menopause and only 30 women who had slight late menopause or had few vasomotor and psychosomatic symptoms presented after 55 year of age (Table 1). The age of presentation depends on severity of symptoms, mental and physical condition of women, dependency on spouse and socioeconomic status of women. 


\section{Occupation, residence and educational status}

In our study most of women $(62 \%)$ were either housewives or were working in farms. As traditionally believed that menopausal symptoms are more in office going women or in educational field, it was not seen in our study, as only $10 \%$ of our group were working in offices (Table 2) so it seems menopausal symptoms are equally common in rural population. The educational status of those women was also poor, as $25 \%$ of them never attended the school, 53\% educated only upto 4th standard (Table 2). Thus contrary to belief, our study had women with low education status and also were from rural area and were either housewife or in farming. This indicates that menopause is no more an urban problem but also women from rural do present with symptoms and require proper attention. In our study $40 \%$ women had no or very little support from the family and came to the hospital with their neighbour. $60 \%$ women mostly from educated family, working in offices, were accompanied by their husbands and they were well aware of their symptoms (Table 3 ).

\section{Menopause and symptoms}

Hot flushes and night sweats are the symptoms most consistently associated with menopause, although their prevalence varies in different cultures. For example, the prevalence has been reported to be $23 \%$ in Thai women (Chompootweep et al), 32\% in Pakistani women (Yahya and Rehan), $45 \%$ in North American women (McKinlay et al). ${ }^{2-4}$ In our study, the prevalence of hot flushes and night sweats was $65 \%$. Many menopausal women complained of dry vagina $(45 \%)$ and $25 \%$ women had vaginal discharge (Table 4). Senile atrophic changes due to estrogen deficiency are the commonest cause for these vaginal discharges. Symptoms of dryness in vagina occurred earlier (1-2 yrs) than vaginal discharge which was found after 5-10 yrs of menopause. Something coming out of vagina (uterine and vaginal prolapse) was present in 112 women and this developed after $>10$ yrs of menopause. $20 \%$ women who had dry vagina also complained of painful coitus, but this occurred after 4-5 years.

In our study the psychosomatic symptoms were significantly present in many women. Most of them had more than one complaint and in many cases these were the leading symptoms next to vasomotor ones. Dizziness (35\%), palpitations (28\%), numbness of extremities $(31 \%)$, irritability $(60 \%)$, tiredness $(48 \%)$, headache (45\%), sleep disturbances $(45 \%)$, muscle and joint pains $(40 \%)$ and weight gain $(30 \%)$ were the various complaints of those women (Table 4). An organic or medical disease was ruled out for some of the symptoms. Most of those symptoms developed in 2-5 yrs of menopause. Similar study was done in Eastern India by Doyeb Dasgupta and Subha Roy. ${ }^{5}$ They found higher psychosomatic and psychological symptoms in their study but our findings are comparable with those of
Sharma $\mathrm{S}$ et al on menopausal women in Jammu. ${ }^{6}$ Urogenital problems were very common and had a significant effect on their daily routine activity. Dysuria $(35 \%)$, frequency $(40 \%)$ and emptying of bladder were significant complaint in 2-5 yrs while stress or urge incontinence occurred in $15-20 \%$ cases after $5-7$ yrs of menopause (Table 4). Thus overall $35 \%$ women had urogenital problems in our study. Shah found that urogenital prolapse was in around $40 \%$. For urinary incontinence it was found that $25 \%$ had stress incontinence, $30 \%$ had mild incontinence whereas urge incontinence was found in $45 \%$ of postmenopausal women. ${ }^{7}$

After analysing the history and presentation all those women were examined in detail. General, breast, thyroid examination, systemic examination and pre abdominal, speculum and vaginal examination was carried out. On examination anaemia (42\%), obesity $(35 \%)$, hypertension $(20 \%)$, cardiovascular disease $(1 \%)$, abdominal mass $(2 \%)$, prolapse of vagina and uterus (28\%), vaginitis (32\%), incontinence (38\%), cervical malignancy $(5 \%)$ and uterine enlargement in $6 \%$ cases (Table 5).

\section{Medical management}

As anaemia, diabetes, hypertension and infections, mostly urinary tract infections were common medical problems in our study, they were treated adequately. Vasomotor symptoms are decreased by various drugs like

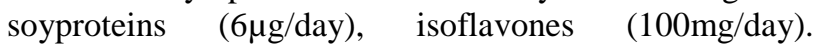
Similarly Kronenberg F, Fugh-Berman used complementary and alternative medicines for menopausal symptoms. $^{8}$ Albertazzi and Etal used dietary soy supplementation on hot flushes. ${ }^{9}$ Medical management was given in 140 cases and 70 required surgical treatment for gynaecological diseases in addition. All the women were also given proper advice about diet, exercise, meditation, and change in lifestyle, weight control and yoga therapy in some cases (Table 6).

As is shown in various studies, those symptoms due to urogenital atrophy respond well to systemic or topical estrogen therapy. In Shah study uro-genital problems can be managed by - Non-hormonal therapy - reassurance, good diet and antioxidant drugs or Hormone replacement therapy - may be systematic and local HRT. ${ }^{7}$ In our study, we didn't use systemic estrogen \& any other hormone. Genitourinary atrophy and symptoms due to the atrophy was treated with local estrogen therapy, and the response was seen in most women. Vaginal estrogen therapy also reduced the urinary symptoms like frequency and urgency and produced the risk of urinary tract infections in post-menopausal women.

In this study 10 cases more subjected to laparotomy with hysterectomy, 36 required vaginal hysterectomy with repair, wertheims hysterectomy was done in 2 case, 12 cases required only vaginal prolapse repair (for cystocoele and rectocoele) and 10 more operated for 
stress urinary incontinence (Table 6). All these women were also subjected to medical treatment, counselling, yoga therapy, meditation, excision and lifestyle changes and collectively the results were analysed.

\section{Counselling and other therapies}

In our study we have adopted basic means of management of menopausal symptoms with various methods like counselling, dietary advice, lifestyle changes, exercise, yoga, meditation, pelvic floor exercise etc. The response was very satisfactory and change in attitude and approach was found after some sessions. Other therapy like vit-E (800 iu/day), acupuncture, exercise show an improvement in vasomotor symptoms. To remain in cool temperature, use of light layered clothing, weight reduction and stoppage of smoking also help in minimizing hot flushes. Physical exercise like walking, running, aerobics in groups and singly were very effective method of change in lifestyle of those women. Though the initial response was not good encouraging, a constant advise about exercise and change in life style helped many women to overcome the symptom, mostly psychosomatic and psychological one (Table 6). Studies by Nelson D. B. Sammel M. D. Freeman E. W. Lin H. Schmitz K also reveal not the anxiety, stress, depression, vasomotor symptom were low in active postmenopausal women compared with inactive women in the same group. ${ }^{10}$ Use of yoga therapy under supervision was advised to more than 50 women. Although the response was slow and not very encouraging, the symptoms were gradually less in the women who practiced yoga regularly. The impact on health and relief from menopausal symptoms were also studied at the Fertility Research Centre and Max Healthcare Centre, New Delhi. ${ }^{11}$ They also found that bone mineral density increased and other menopausal symptoms decrease in women who practiced yoga regularly.

\section{CONCLUSIONS}

This study was conducted in 200 women with menopausal symptoms over period of 3yrs.Average age of menopause of our study is $46.5 \mathrm{yrs}$ in our study. The symptoms were more common in housewives and rural women. The presenting women were mostly from illiterate class or with education upto $4^{\text {th }}$ standard. $60 \%$ were well supported by their family and husband. Vasomotor symptoms, coital problems, psychological and psychosomatic problems were most common presentations. Counselling, medical management, yoga, meditation, lifestyle changes, phytoestrogens and in selected cases use of local estrogen, were the modalities for treatment. Most of patients responded well.

There is need of setting menopausal clinics and centres to help women with symptoms and have signs of estrogen deprivation. Counselling and education are main treatment modalities.

\section{ACKNOWLEDGEMENTS}

We sincerely thank Dr Ajay Chandanwale sir, Dean B.J. Govt. Medical College and Sassoon hospitals Pune, all staff members of our department, Department of anaesthesiology and all our patients.

\section{Funding: No funding sources}

Conflict of interest: None declared

Ethical approval: The study was approved by the Institutional Ethics Committee

\section{REFERENCES}

1. Marc A, Leon Speroff. Menopause and perimenopause transition: Clinical Gynecological Endocrinology and Infertility. 8th ed. South Asian edition: Lippincott Williams and Wilkins. 2013:6802.

2. Chompootweep S, Tankeyoon $\mathrm{M}$, Yamarat $\mathrm{K}$, Poomsuwan P, Dusitsin N. The menopause age and climacteric complaints in Thai women in Bangkok Maturitas. 1993;17:63-71.

3. Yahya S, Rehan N. Age, pattern and symptoms of menopause among rural women of Lahore. J. Ayub Med. Coll. Abbottabad. 2002;14:9-12.

4. McKinlay S, Brambilla D, Posner J. The normal menopause transition. Am. J. Hum. Biol. 1992;4:3746.

5. Dasgupta D, Ray S. Menopausal Problems among Rural and Urban Women. Eastern India. Journal of Social, Behavioral, and Health Sciences. 2009;3:2033

6. Sharma S, Tandon VR, Mahajan A. Menopausal Symptoms in women of Jammu. JK Science. 2007;9(1):13-7.

7. Shah M. Menopausal uro-genital problems and remedy.2005 Cited from Souvenir of IMS Conference. Xth Annual Conference of Indian Menopause Society, Ahmedabad. 2005.

8. Kronenberg F. Fugh-Berman. Complementary and alternative medicines for menopausal symptoms. A review of randomized control trials- Ann. Intern med. 2002:805-14.

9. Albertazzi. The effect of dietary soy supplementation on hot flushes. Obs-Gyn. 1998;91:6-11.

10. Nelson D, Sammel D, Freeman W, Lin H ,Schmitz K. Effect of physical activity on menopausal symptoms amongs urban women, Medicine and science in sport and exercise. 2008;50:8

11. Telang M, Chakaravarty D. Study of effect of yoga in menopausal problems. Journal of Obstetrics and Gynecology. 2004;9(10):676-8.

Cite this article as: Patil SS, Sambarey PW, Patil CS. Menopausal syndrome: clinical presentation and management. Int J Reprod Contracept Obstet Gynecol 2016;5:757-61. 